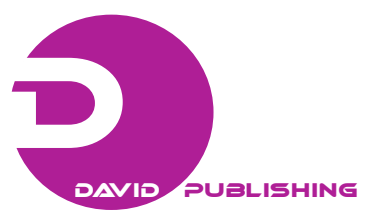

\title{
The Impact of the Maputo Development Corridor on Wealth Creation within the Region It Serves
}

\author{
Maria Magdalena Campbell ${ }^{1}$ and Andries Carl Hauptfleisch ${ }^{2}$ \\ 1. Department of Urban and Regional Planning, Faculty of Natural and Agricultural Sciences, University of the Free State, \\ Bloemfontein 9300, South Africa \\ 2. Department of Quantity Surveying and Construction Management, Faculty of Natural and Agricultural Sciences, University of the
} Free State, Lynnwood Ridge 0040, South Africa

\begin{abstract}
The Maputo Development Corridor along the N4 toll road between the north-eastern provinces of South Africa and Maputo (the capital and main port of Mozambique) was initiated in 1996. A Development Corridor can be seen as a concept to elevate an area to a certain level of development. One of the objectives of this project was investment in transport infrastructure in order to create an enabling environment for economic growth and development. The project is also in line with the 1995 Spatial Development Initiatives of the South African Government that attempt to improve investment in those areas were the greatest potential for growth exists. This paper addresses economic wealth creation within the broader region that the N4 toll road and the corridor currently serve. The research revealed that the areas closer to the N4 corridor had higher growth in terms of economic output as measured by Gross Valued Added than those further removed. There were a stronger correlation between growth in employment and proximity to the road corridor for the manufacturing, construction, trade and transport sectors. Analysis done also shows that income per capita has grown at a faster rate in areas closer to the corridor that areas further removed.
\end{abstract}

Key words: Maputo development corridor, social-economic, economic growth and development, appraisal, transport infrastructure, anchor projects, SDI (spatial development initiative), development corridor.

\section{Introduction}

In mid-2008 TRAC (Pty) Ltd (Trans African Concessions) requested a multi-disciplinary research team of the University of the Free State and the CSIR (Council for Science and Industrial Research) Built Environment to initiate a socio-economic impact study on the MDC (Maputo Development Corridor) along the N4 toll road. TRAC is the Concessionaire of the R3 Billion ( $1 \mathrm{R}=13 €$ ) projects to build, finance, operate, maintain and expand the $630 \mathrm{~km} \mathrm{~N} 4$ toll road stretching from Pretoria in the Gauteng Province, in South Africa, through the Mpumalanga Province to Maputo in Mozambique (Fig. 1). The Maputo Development Corridor is one of the most ambitious and exciting initiatives undertaken within the Southern

Corresponding author: Maria Magdalena Campbell, $\mathrm{PhD}$, research fields: planning for social and spatial excluded communities. E-mail: campbemm@ufs.ac.za.
African region. The vision is to rehabilitate the core infrastructure, i.e., road, port and dredging, electricity and the border post within the Corridor, through public/private partnerships, thereby re-establishing key linkages and opening up inherent under-utilized economic development opportunities. Underlying the vision is the desire to see this initiative contributing to other key policy areas - notably regional economic integration, international competitiveness and a broadening of the ownership base in the economy of the Corridor. In order to facilitate the implementation of the project in partnership with the private sector, protocols were signed between the two Governments of South Africa and Mozambique [1].

An understanding of economic forces is vital to any development planning as people and businesses will only locate in areas where it is economical viable. The idea of the National Physical Development Plan (RSA, 


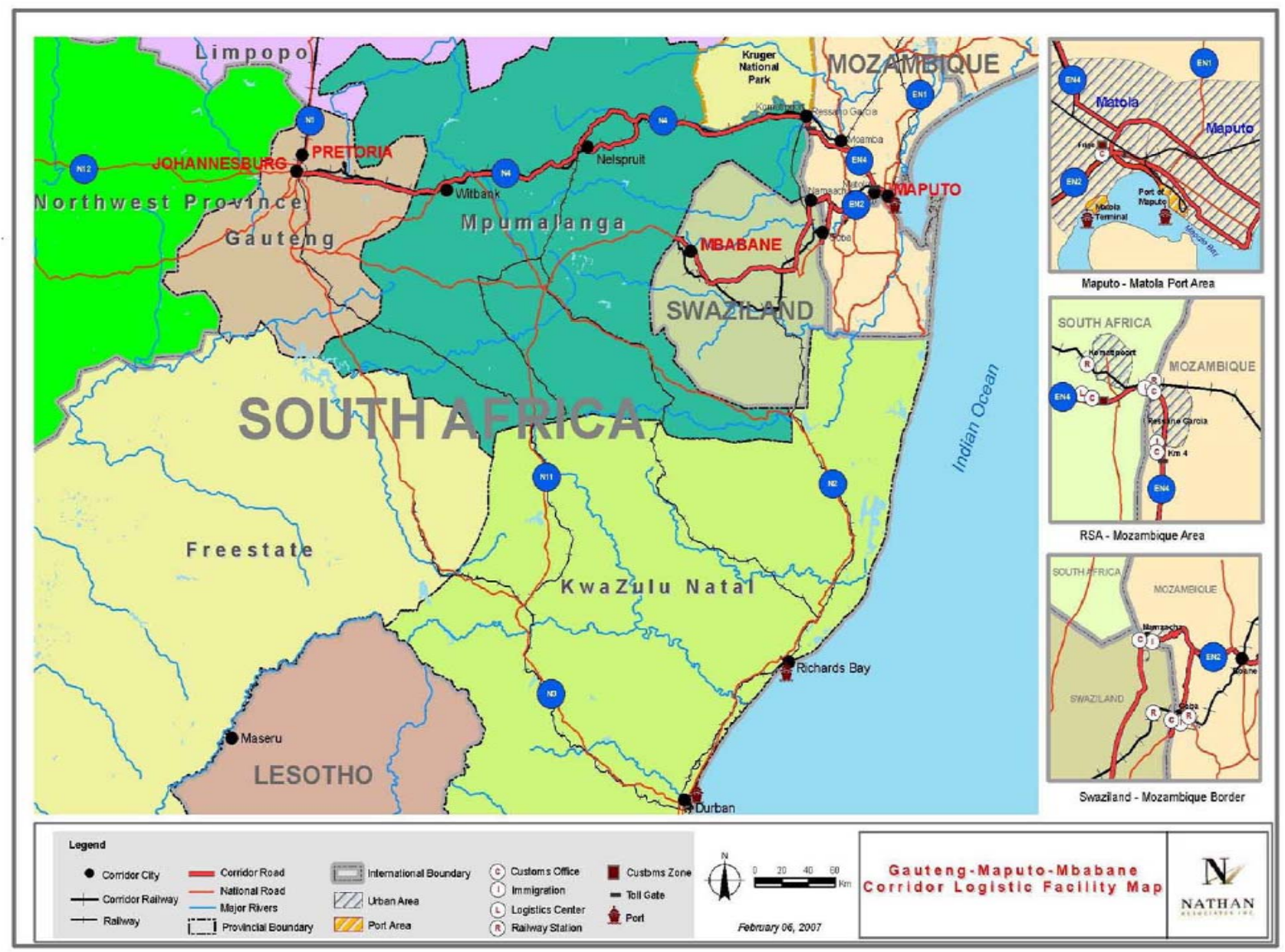

Fig. 1 Maputo development corridor [2].

[3]) of 1975 was to link existing metropolitan areas with identified or future growth poles by means of development axes. Geyer [4] found that some of these axes were not supported by secondary development centres or were stretching over too long distances to make development realistically viable. The greater the distances between centres, the stronger these secondary centres must be as a propelling force. In some cases these so-called axes were not axes at all but rather finger developments with no equilibrant pole at the other end. The development of a good road network which provides better interaction with the hinterland in many cases led to the decline of economic activities in small towns as the threshold "time" to bigger centres was changed. The SDI's (Spatial Development Initiatives) of the South African Government, conceived in 1995 by the Cabinet was an attempt to improve investment in those areas where the greatest potential for growth exists (Fig. 2) [5]. The Maputo Development Corridor is a typical axis development between two big centres but taking economics into consideration, as Maputo is the closest harbour to Gauteng and in the 1970s, $40 \%$ of the export from Gauteng went through this port, this faded away due to socio-political reasons. [5]

Although other studies investigated the impact of the MDC (Maputo Development Corridor) it is clear that subsequent deductions are matters of interpretation. Some changes cannot clearly be related to the MDC. This paper revisits concepts related to corridors and their theoretical foundation. Some sectors and components of socio economic development have been included as well as main activities that occurred since the inception of the MDC. There are clear deficiencies 


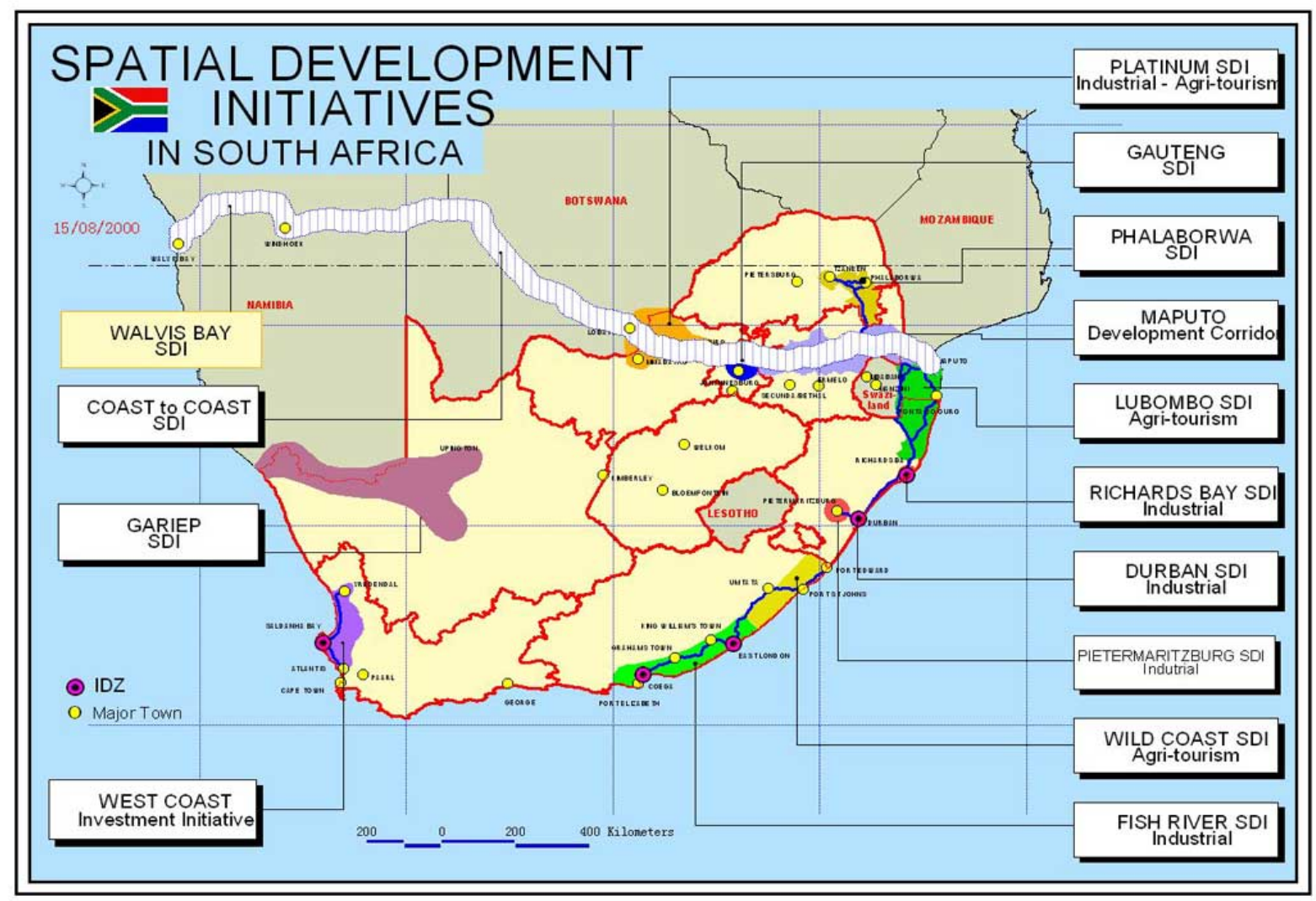

Fig. 2 Spatial development initiatives [6].

and constraints (example: the coverage of Mozambique and Swaziland) in the picture currently. This should therefore be seen as an initial scan of only what is available. It must be emphasised that the focus was also on the road component of the MDC.

Major changes occurred in the Mpumalanga province. The most obvious deductions relate to freight and people movements directly related to the usage of the road and port. Other implications are indirect and thus assumed. The socio-economic issues addressed do not clearly point to the Maputo Corridor as the main contributor to changes in socio-economic conditions. In fact, some issues appear to be worse off for example unemployment in Mpumalanga. Although the Maputo Corridor is a complete entity stretching from Gauteng to Maputo, the information to be presented focused on the South African side particularly within/along the Mpumalanga province (Fig. 1). Mpumalanga's growth (for the period of analysis: 1996-2002) in terms of economic output as measured by GVA (Gross Value
Added), was on par with South Africa as a whole. The analysis did however indicate that areas closer to the N4 corridor (axis) had higher growth than those further removed. This is the case for total output as well as for several sectors. GVA per capita also indicated a similar situation - areas close to the road corridor had a higher growth rate than those further removed.

As regional development along the MDC is significant and since it is a focal point of this paper, development corridors will be put in context followed by the main findings of the research.

\section{Contextualising Development Corridors}

From a developmental point of view, the concept of "regional development" can be included in "economic development" that results in the creation of wealth. Thus, regional development can involve intervention by the Government in the spatial developmental planning process. 


\subsection{Theoretical Perspective}

The term "regional development" is defined as follows: "Regional development concerns the incidence of economic growth. It is ultimately the result of the location of economic activities in response to differential regional attractions. Shifts in the location pattern have direct repercussions on income, employment and welfare. Since spatial organisation is a function of activity and interacting patterns, regional development is simply an expression of these patterns”. Bingham [7] and Mier [8] argue that, "The term refers to change in regional productivity as measured by population, employment, and income and manufactured value added." In view of the above-mentioned definition, regional development includes different aspects such as political, social and economic factors, taking place within a supra-urban framework.

In order to promote regional economic development, the SADC (Southern Africa Developing Community) must be seen as one entity consisting of a number of broad developmental regions that may extend beyond the boundaries of various independent states where a Development Corridor can be seen as a concept to elevate an area to a certain level of development. The area must have the potential to develop, on the condition that the entire area must take part in the process [9].

The fact that development takes place within a corridor implies that we are referring to a specific spatial area in this regard. The delimitation of such an area depends on the type of development planned. However, certain conditions apply, since the development of a corridor is aimed firstly at developing the region from the inside, and then making contact and developing further extensions with adjoining regions from there. A Development Corridor is therefore a multi-dimensional strategy that further strengthens and supports the chosen area's internal development networks [9, 10].

\subsection{Policies and Legislation}

The regional SDIs (Spatial Development Initiatives) are projects identified on the basis of their inherent under-utilized economic potential. Their developmental objective is to create sustainable jobs in these areas by identifying and facilitating new investment. The mechanism by which this is achieved is focused, coordinated action at all levels of government and by all relevant line functions within the spatially defined area, in order to remove blockages to investment. The SDIs are part of the GEAR (growth employment and redistribution) strategy. This macro-economic strategy developed by the South African government in 1996 aims to strengthen economic growth in the country while broadening employment opportunities as well as the redistribution of economic opportunities and income to the advantage of the poor [11]. Therefore as part of GEAR the SDIs fit into a broader macro-level strategy of simultaneously expanding the economy, stabilising conditions for sustained growth and opening up economic opportunity and employment prospects for previously disadvantaged sectors of the South African population [5].

Spatial Development Initiatives is a key industrial policy committed to foster sustainable industrial development in areas where poverty and unemployment is at its highest. This objective is carried out through the SDI which focuses high-level support in areas where social-economic conditions require concentrated government assistance and where inherent economic potential exists [12].

The SDI concept (Fig. 2) may have a variety of focuses, such as:

- Industrial - KwaZulu-Natal and Fish River SDIs. The Fish River SDI had inspired nine new commercial operations, which created 500 new jobs. New firms invested R156 million in the Eastern Cape province;

- Agro-tourism - Lebombo SDI and Wild Coast SDI; 
- Sectoral mix - Maputo Development Corridor;

- Industrial development zones (IDZs) - Coega, Saldanha and East London.

Second Generation SDI: The Gauteng SEZ (Special Economic Zone) focuses on high technology manufacturing, information technology, telecommunications, food processing, cultural activities, etc. [13]. At the height of the SDI programme consists of 11 local SDIs and four IDZs at varying stages of delivery. They are the following:

- SDIs: Maputo Development Corridor, Lebombo SDI, Richards Bay SDI, including the Durban and Pietermaritzburg nodes, Wild Coast SDI, Fish River SDI, West Coast Investment Initiative, Platinum SDI, Phalaborwa SDI, and Coast 2 Coast Corridor;

- SEZs: Gauteng SEZ;

- IDZs: Coega IDZ, East London IDZ, Saldanha IDZ and Richards Bay IDZ.

Primarily all the major projects in the SDI are based on a partnership between the public and private sectors, and are set to provide opportunities for participation in sectors such as agriculture, mining, tourism, environment, forestry, infrastructure and ports. These projects were expected to create more than 68,000 new jobs. A key component of this initiative is the move away towards international competitiveness, regional co-operation, and a more diversified ownership base [12].

The SDI programme is an interdepartmental investment strategy led by the national DTI (Departments of Trade and Industry) and Transport (DOT) and involves strategic initiatives by government aimed at:

- Crowding in of investment: This investment (including financial, technical and institutional resources) can not only be made by the public sector and its parastatal agencies, but must also make sense for the private sector. The crowding-in effect has been strengthened by the fact that some of the infrastructure development projects that were previously funded by the public sector are increasingly being funded by way of private sector investment and lending;

- PPPs (public-private partnerships);

- inherent economic potential;

- rapid planning and delivery;

- restructuring the "apartheid" space economy;

- generating sustainable employment;

- maximising private sector investment;

- exploiting SA's under-utilised locational and economic advantages.

Certain SDI's are also beyond the confines of South Africa's borders where the economic imperatives of the strategy dictated that the SDI includes part of a neighbouring country. Examples are the Maputo Development Corridor between South Africa and Mozambique (but it also affects Swaziland, Zimbabwe and Botswana), and the Lebombo Initiative between South Africa, Mozambique and Swaziland. Under consideration is the extension of the Rustenburg SDI to include the Trans-Kalahari transport corridor between Namibia and Botswana.

The South African SDIs all matured in the early 2000s and either became provincial initiatives (like the IDZs, for example the Lebombo as referred to above) or fizzled out - like the West Coast Investment Initiative and Platinum SDI. None of the old South African SDIs are being pursued as part of the 2001/2 Regional SDI Programme. However, one or two of the provinces appear to have adopted the methodology and talk of corridors in their Provincial Growth and Development Strategies [13].

Ten development initiatives have been designated such as the regional development programmes or development corridors and have already generated around 400 investment projects valued at R83-billion [12] such as the Maputo Development Corridor. The key infrastructure projects are the N4 Maputo Corridor toll road, the upgrading of the railway line from Ressano Garcia to Maputo, the upgrading of the Maputo Port, the dredging of the harbour and finally, telecommunications. The first phase of the corridor, the N4 toll road construction was launched on June 6, 1998. 
The transport axis between Gauteng, the industrial heart of South Africa, and Maputo offers the shortest link to an export harbour.

\section{Main Findings and Deductions of Literature Review Process}

The following figures contain a spatial analysis of the economic output of Mpumalanga, using GIS technology and drawn from the study.

\subsection{Economic Output-Gross Value Added}

The concept of Gross GVA (Geographic Value Added) — which is used by the firm Global Insight as a basis for making estimates of regional economic activity — is broadly similar to what is more generally known as GGP (Gross Geographic Product). In essence: GVA (factor cost) = Compensation of employees + Gross Operating Surplus [14].

Analyses were done for each of the nine sectors of the Mpumalanga provincial economy, but only the following most applicable ones to this study are shown namely:

- Agriculture, forestry and fishing;

- Mining, quarrying;

- Manufacturing;

- Electricity, water;

- Construction;

- Transport, communications;

- Finance, real estate.

On these figures, areas revealing a high annual growth for a given indicator are awarded a darker shade than areas with a lower growth. This makes it possible to visually detect spatial patterns over the analysis period. For each spatial entity (district), growth for that area is also shown in the form of bar charts, the first bar indicating the indexed value at the start and the second bar the value at the end of the analysis period.

From the "All sectors" figure (Fig. 3) it is clear that areas in close proximity of the transport infrastructure spine grew at a higher rate than areas further removed from the corridor. As regards the individual sectors of the economy this pattern is less pronounced in the case of agriculture and mining, as they are location/resource-dependent and therefore less dependent on an intervention such as the MDC. In the case of the other sectors, these maps show that growth in the vicinity of the MDC outperformed growth in areas further removed from the corridor.

\subsection{Employment Status}

The analysis of first phase study [15] firstly involved an analysis of the breakdown of employment in Mpumalanga by economic sector and spatial area. For total employment (all sectors combined), Fig. 4 shows a moderately higher growth in employment in the districts towards the east of the study area. This is also reflecting in Fig. 5. The change (increase/decrease) in employment for the most important sectors of the economy was then compared with the corresponding figures for the provinces of KwaZulu-Natal, Gauteng, Limpopo as well as South Africa. Finally, a spatial analysis of employment at sector and district level was undertaken by focusing on changes in growth rates over the analysis period.

As regards the relative importance of economic sectors, Fig. 6 shows the dominance of trade in terms of employment. This is followed by the community service, manufacturing and agriculture sectors, each approximately half of the size of the trade sector.

As with regards to the relative importance of districts, Fig. 6 confirms the dominance of Nelspruit, Witbank, Middelburg and Highveld Ridge as major employment centres. It is also notable that these areas are all located on the N4-road.

As regards a comparison of Mpumalanga with other provinces, Fig. 7 shows that the growth rate in employment in Mpumalanga's trade sector, with an annual increase of more than 15 per cent p.a., is well above the South African average growth rate of about 12 per cent p.a. and also more than 50 per cent higher than that of Gauteng, the economic hub of South Africa. 


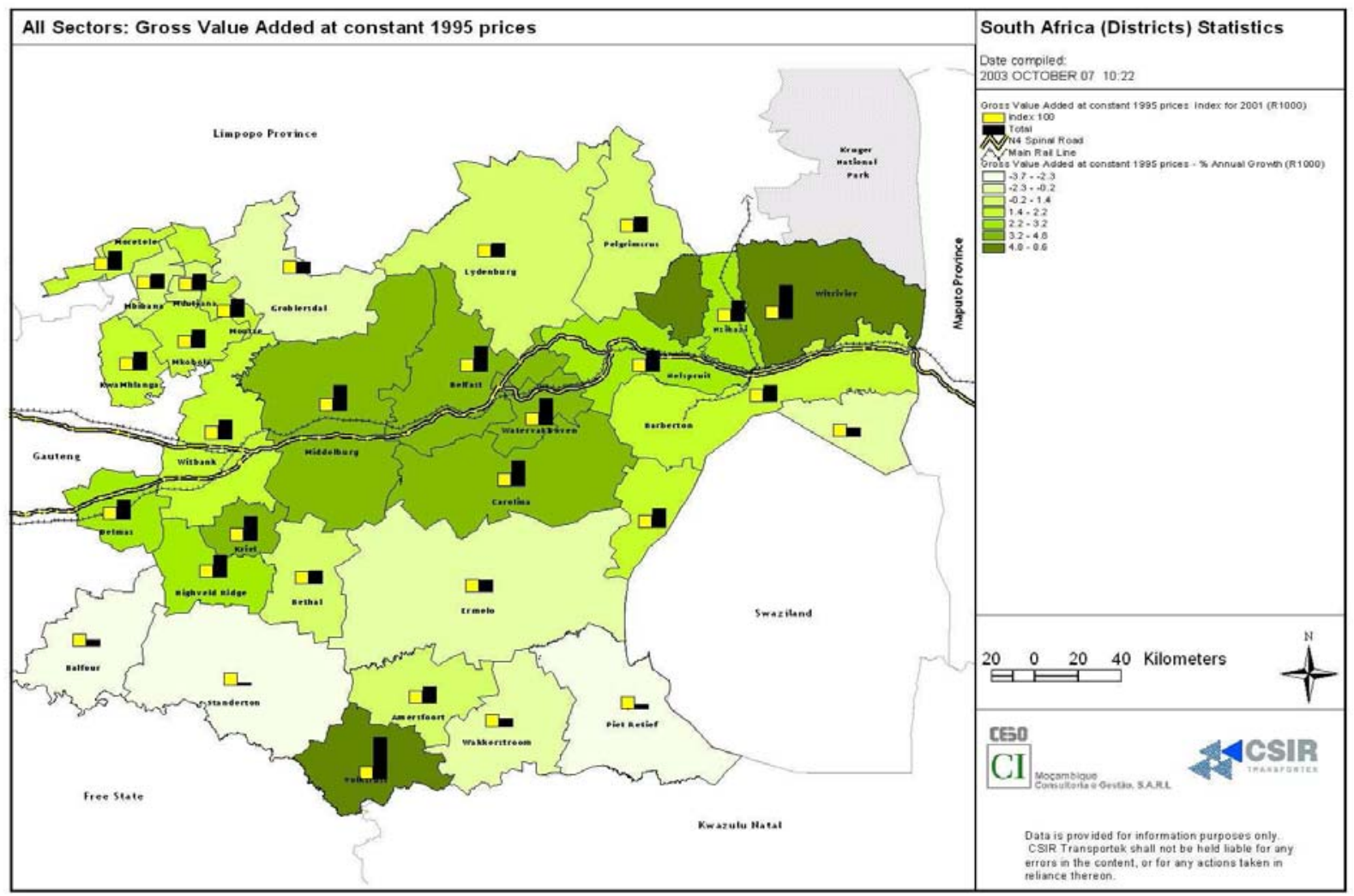

Fig. 3 Rate of change during the analysis period: Gross value added (all sectors) [15].

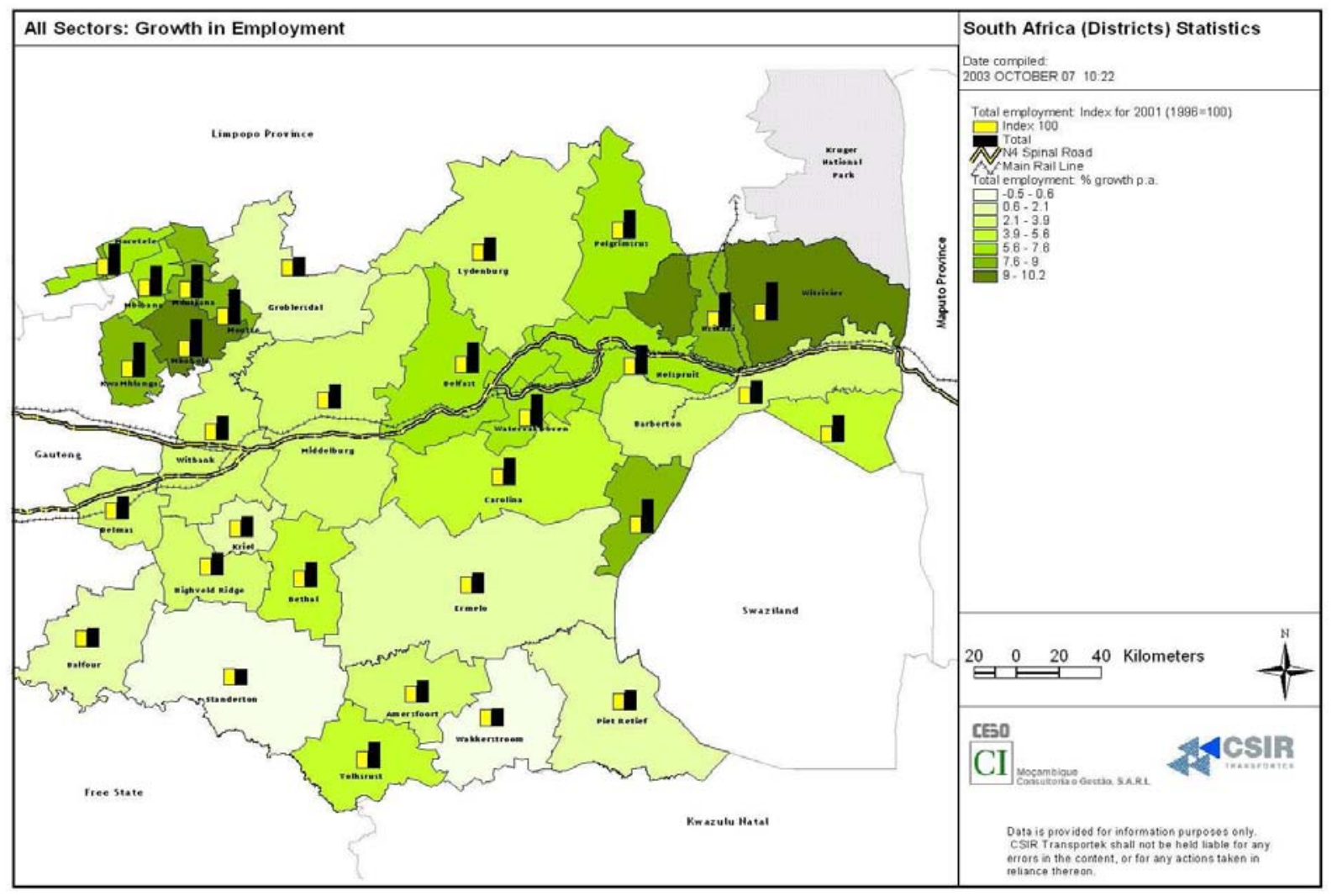

Fig. 4 Rate of change during the analysis period: employment (all sectors) [15]. 


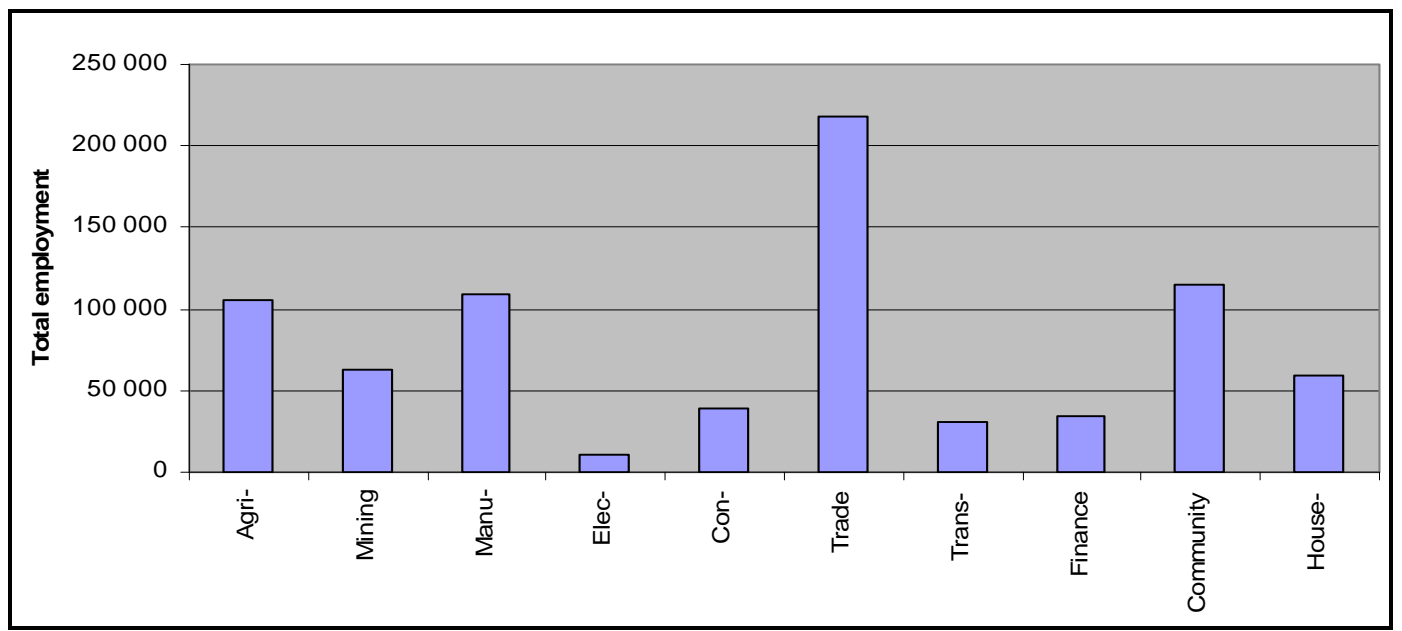

Fig. 5 Mpumalanga employment per economic sector, 2001 [16]

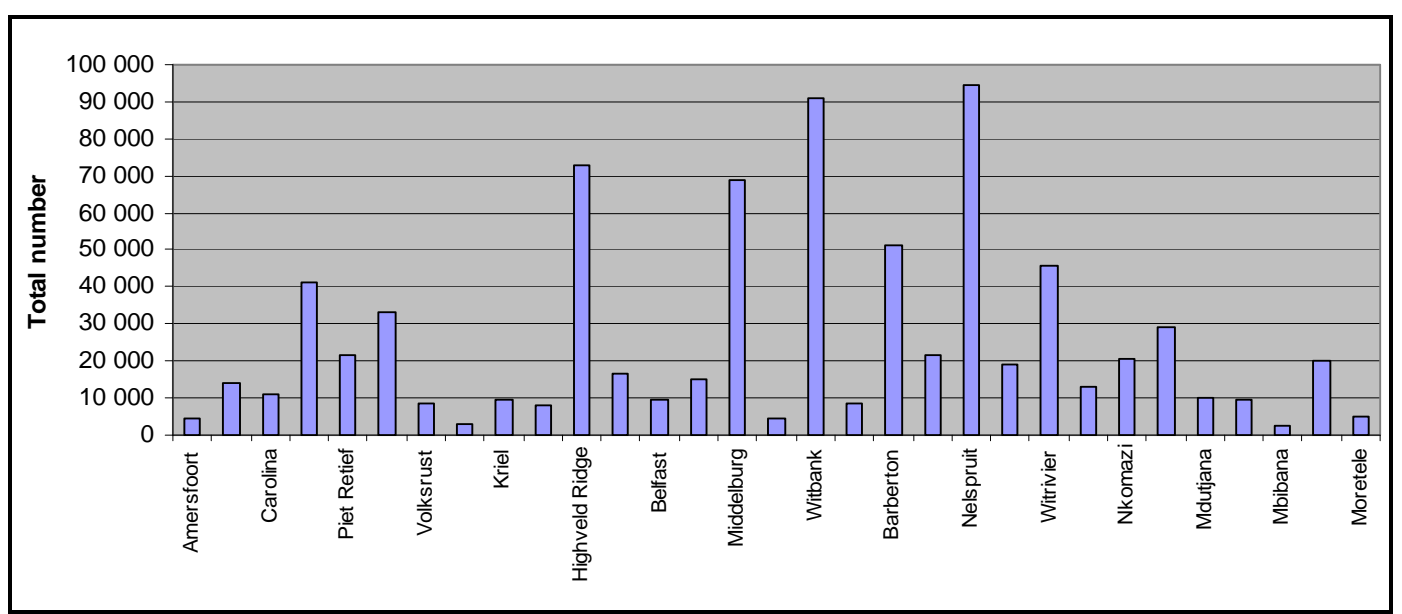

Fig. 6 Mpumalanga employment by local municipality, 2001[16]

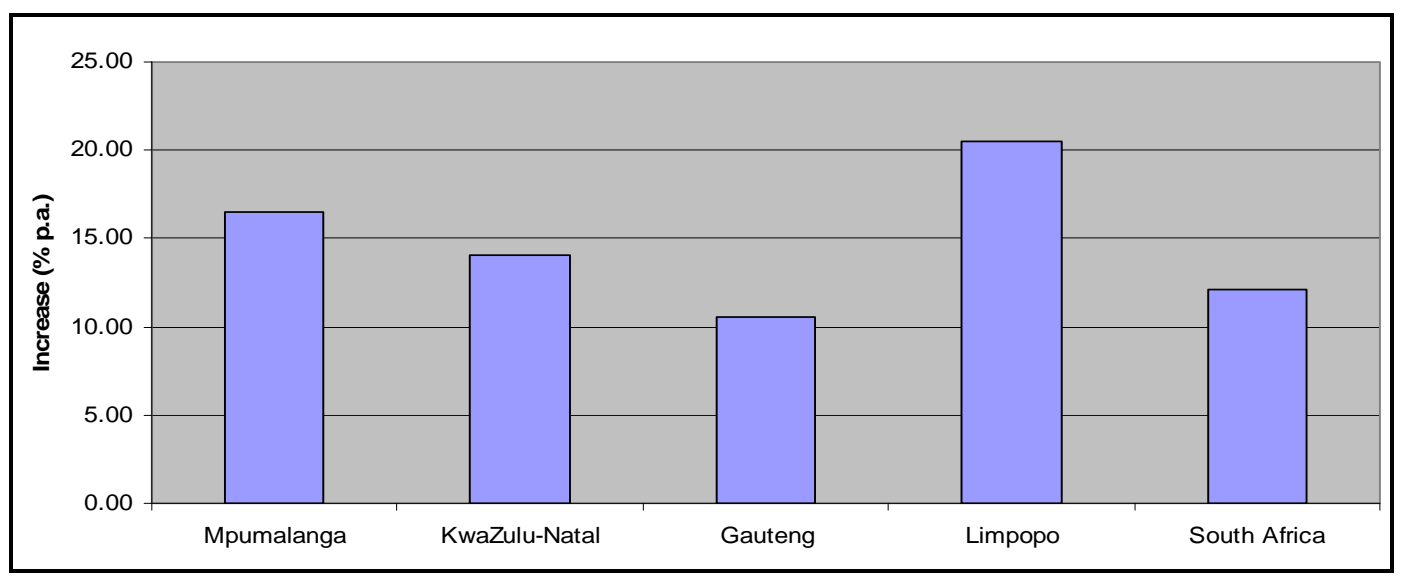

Fig. 7 Mpumalanga: Trade increase in employment, 1996-2001 [16]

\section{Conclusions and the Way Forward}

The MDC was initiated for a number of specific objectives, these objectives according to [15] constitute a mixture of "enabling factors" (e.g., investment in transport infrastructure and institutional arrangements with the aim of creating an enabling environment for economic growth and development) and "desired 
outcomes” (e.g., positive macro-and socio-economic impacts that are sustainable in terms of their impact on the environment.

The benefits of the Maputo Corridor Development Initiative may be summarised as:

- The stimulation of trade via competent infrastructure;

- The opening up of South African markets to Mozambican producers and access to global markets through the development of Maputo Port;

- Employment creation through increased economic activity in Maputo and along the Corridor, with the ability to shift to higher value-added industry sectors;

- Increased access to international tourism;

- Improved income generation through the encouragement of private investment;

- Saving of public sector financial resources through the use of private sector investment in infrastructure development. [1]

Private businesses have been cooperating recently through the MCLI (Maputo Corridor Logistics Initiative) to promote the development and use of the Maputo Development Corridor. The MCLI was formed in 2004 to support the development of the Maputo Corridor into a sustainable, efficient transportation route, creating an increasingly favourable climate for investment and new opportunities for communities along the corridor The following stakeholders from South Africa, Mozambique, and Swaziland supported MCLI: government departments, cargo owners, road haulers, intermodal operators, rail service providers, logistics companies, clearing agents, forwarding agents, shipping lines, port agents, shipping brokers, professional bodies, associations, financial institutions, border post management, and officials [2, 17].

An entire region must take part in the development process and for a development axis the two development centres must be linked by means of a communication axis. There must be mutual dependency between the centres, the interaction must have the potential for further development and the axis must grow both economically and physically.

The literature review included mostly quantitative items, and utilized statistics sourced from various reports. The way forward will comprise of an empirical research phase when qualitative interviews with the business sector will be done. Inputs from main stakeholders such as local authorities, planners, business chambers, community organizations, NGOs involved in development, and the private sector, will be sought. Although such inputs would be qualitative it would present a highly valuable input.

\section{References}

[1] Trans African Concessions (Pty) Ltd. n.d. N4 Toll Route TRAC, www. TRACN4.co.za (accessed July 2, 2008).

[2] Nathan Associates Inc., Maputo Corridor Summary Report, a Transport Logistics Diagnostic Tool Study, USAID (United States Agency for International Development), 2008.

[3] RSA (Republic of South Africa), National Physical Development Plan-NPDP, Government Printer, Pretoria, 1975.

[4] H. S. Geyer, Translated as: The development axis in physical planning, Ph.D. Thesis, Potchefstroom University for Christian Higher Education, Department of Urban and Regional Planning, Potchefstroom, 1986.

[5] P. Jourdan, Spatial development initiatives (SDIs) — The official view, Development Southern Africa 15 (5) (1998) 717-725.

[6] CSIR (Council for Science and Industrial Research) Transportek, Spatial Development Initiatives, 1996.

[7] J. Glasson, An Introduction to Regional Planning: Concepts, Theory and Practice, UCC Press, London, 1978.

[8] R. D. Bingham and R. Mier, Theories of Local Economic Development: Perspective From Across the Discipline, SAGE Publications, London, 1993.

[9] Infrastructure Development Corridor, Infrastructure Development Corridor, available online at: http://www.schillerinstitute.org/economy/maps2.html.

[10] M. Link, Canal network, available online at: http://www.felkirk-wheel.com/heel/information/corridor. html.

[11] C. Du Plessis and K. Landman, Sustainability Analysis of Human Settlements in South Africa, CSIR, Pretoria, 2002.

[12] South Africa Information/doing business/economic development, South Africa Information/doing 
business/economic development, available online at: http://www.southafrica.info.

[13] D. Perkins, Official of the Regional Spatial Development Initiative Programme Unit of the DBSA (Development Bank of Southern Africa), Personal communication on an update of the South African SDI'S, Feb. 16, 2009.

[14] GAP (Geospatial Analysis Platform), A common spatial analysis platform jointly developed by the Presidency, the
DTI (Department of Trade and Industry) and the CSIR (Council for Science and Industrial Research), 2007.

[15] I. Schutte and A. Francisco, Maputo Development Corridor: Evaluation of First Phase, 2004.

[16] Statistics South Africa, Census 2001, Statistical release, available online at: http://www.statssa.gov.za/census01/html/default.asp.

[17] Maputo Corridor Logistics Initiative, MCLI corporate profile, available online at: http://www.mcli.co.za. 